\title{
Difference between upper and lower limb blood pressure in normal neonates using Doppler technique
}

\author{
M. DE SWIET, J. PETO, and E. A. SHINEBOURNE \\ From the Department of Paediatrics and the M.R.C. Tuberculosis and Chest Diseases Research Unit, Cardio- \\ thoracic Institute, Brompton Hospital; and Queen Charlotte's Maternity Hospital, London \\ de Swiet, M., Peto, J., Shinebourne, E. A. (1974). Archives of Disease in \\ Childhood, 49, 734. Difference between upper and lower limb blood pressure \\ in normal neonates using Doppler technique. Using the Doppler technique, \\ systolic upper limb blood pressure was found to be greater than lower limb blood \\ pressure (mean difference $17 \mathrm{mmHg}$ ) in 20 normal neonates. Therefore, the finding \\ of such a difference does not necessarily signify the presence of a pathological degree of \\ coarctation of the aorta.
}

It has been suggested that upper limb blood pressure is greater than lower limb blood pressure in the neonate (Goldring and Wohltmann, 1952; Moss, Liebling, and Adams, 1958). This is the reverse of the normal adult situation (Hamilton, Woodbury, and Harper, 1936). Since a pressure difference of more than $20 \mathrm{mmHg}$ between the upper and lower limbs is usually considered to be evidence of coarctation of the aorta (Goldring and Wohltmann, 1952; Moss and Adams, 1968), and since a reliable noninvasive technique has become available for the measurement of blood pressure in infants (Elseed, Shinebourne, and Joseph, 1973), we have further investigated the difference in systolic blood pressure between upper and lower limbs.

\section{Method}

We selected 20 term normal neonates who had a normal delivery after a normal pregnancy. Their right upper and lower limb systolic blood pressures (ULBP and LLBP) were measured at the same time of day (about 11 a.m.) on 6 successive days after the day of delivery, by the Doppler shift technique (Elseed et al., 1973). All measurements were made on supine infants who were asleep or awake but not crying.

A $5 \mathrm{~cm}$ cuff was placed snugly around the upper limb above the elbow or the lower limb above the ankle. The ultrasound probe* was placed over either the brachial or posterior tibial artery, and the cuff was inflated to 200 $\mathrm{mmHg}$. It was then deflated at no faster than 6 $\mathrm{mmHg} / \mathrm{sec}$ and the cuff pressure at which continuous

Received 4 March 1974.

^Parks Electronics Laboratory Model No. 802, distributed by Instrumentarium Ltd. rhythmical Doppler sounds could be heard was taken as the systolic pressure (Elseed et al., 1973). On each day 3 measurements of ULBP and 3 measurements of LLBP were made within 5 minutes and the means of these measurements were subsequently analysed. The order of measurements was randomized.

\section{Results}

Of the 120 simultaneous means of measurements of ULBP and LLBP, 101 were analysed. Measurements originally made when the babies were feeding were subsequently discarded because of the increase in variability of systolic blood pressure that occurred at that time. The ULBP was $95 \pm 2 \mathrm{mmHg}$ (mean $\pm \mathrm{SEM})$. ULBP was greater than LLBP (difference $17 \pm 2 \mathrm{mmHg}$ ). Both ULBP and LLBP tended to increase over the 6-day observation period. Transient changes in ULBP were more marked than corresponding changes in LLBP. Assuming that ULBP was the better measure of aortic blood pressure we fitted a linear model to predict LLBP.

Multiple regression analysis gave the following equation where $d$ is day number ( 1 to 6$)$ :

$\mathrm{LLBP}(\mathrm{mmHg})=0.35 \mathrm{ULBP}(\mathrm{mmHg})+2 \cdot 8 \mathrm{~d}+$ 38.8; Equation 1. $\mathrm{r}=0.56$. $\mathrm{P}<0.001$ for each variable.

Thus the difference between ULBP and LLBP decreased as a function of age. Regression analysis of ULBP on age alone showed that ULBP increased by $2 \cdot 1 \mathrm{mmHg} /$ day. Substituting in equation 1 , this predicted that LLBP should increase by 3.5 $\mathrm{mmHg} /$ day. This was confirmed by separate regression of LLBP on age which gave an increase of 
$3.6 \mathrm{mmHg} /$ day. The difference between ULBP and LLBP should therefore decrease by approximately $1.5 \mathrm{mmHg} /$ day. For simplicity we have fitted linear models; however, there was some evidence that ULBP increased most rapidly between the third and fifth days. We therefore repeated the analyses fitting separate means for each day and achieved substantially the same results. The difference between ULBP and LLBP was not related to the order in which the measurements were made.

\section{Discussion}

We have shown that ULBP was consistently greater than LLBP. It is unlikely that this apparent difference was due to measurement artifact. It has been shown that there is no systematic difference between measurements of systolic blood pressure obtained by the Doppler technique and direct intra-arterial measurements (Elseed et al., 1973). Errors in sphygmomanometry in infants largely depend on the relation between cuff size and limb size (Long, Dunlop, and Holland, 1971). Since there was no systematic difference in the circumferences of the upper and lower limbs at the positions where we measured blood pressure, the observed difference in pressure is unlikely to be an effect of cuff size.

Moss et al. (1958) noted that ULBP was greater than LLBP using the flush technique. They found a mean difference of $6 \mathrm{mmHg}$ in the first week of life; there was no difference by 10 months, and the difference had reversed by 12 months (LLBP greater than ULBP by $4 \mathrm{mmHg}$ ). The mean difference of $17 \mathrm{mmHg}$ which we observed in the first week was greater than that found by Moss et al. (1958). This was principally due to different measurement techniques. The Doppler technique gives an accurate systolic blood pressure (Elseed et al., 1973), whereas the flush technique underestimates systolic blood pressure and correlates poorly with mean blood pressure (Elseed et al., 1973; Moss and Adams, 1964). Hamilton et al. (1936) had found that systolic LLBP was greater than ULBP in the adult. Moss et al. (1958) suggested that the difference between ULBP and LLBP that they noted was only a difference in mean blood pressure rather than in systolic blood pressure, and they therefore did not believe that the neonatal relation was necessarily different from that in the adult.

We found a systolic pressure difference of $17 \pm 2$ $\mathrm{mmHg}$ (mean \pm SEM; SD $17 \mathrm{mmHg}$ ) between the upper and lower limbs in normal babies. Because of the variability in the observations it is more meaningful to express the results in terms of extreme values. Nineteen observations showed a pressure difference between 20 and $30 \mathrm{mmHg}$, and 16 observations showed a difference greater than 30 $\mathrm{mmHg}$. Since these were all normal babies we suggest that in the first week of life a difference of at least $30 \mathrm{mmHg}$ may be within normal limits. Furthermore, we suggest that all neonates may have a degree of physiological coarctation of the aorta. The most obvious site for the resistance accounting for this pressure difference is the aortic isthmus, the portion of the aorta between the origin of the left subclavian artery and the ductus arteriosus (Rudolph, Heymann, and Spitznas, 1972; Shinebourne, 1974).

Because of the contribution of the ductus arteriosus to aortic blood flow, the isthmus is relatively underperfused, receiving only $25 \%$ of the combined cardiac output in the fetus (Rudolph et al., 1972). The dimensions of the blood vessels cannot immediately change to account for the difference between the fetal and adult blood flow patterns. We believe that the effect of the aortic isthmus persists and accounts for the difference between upper and lower blood pressures in the neonate.

We thank the nurses and patients of Queen Charlotte's Hospital for their co-operation, and Mrs. Susan Cowley for help in the preparation of this manuscript.

\section{REFERENCES}

Elseed, A. M., Shinebourne, E. A., and Joseph, M. C. (1973). Assessment of techniques for measurement of blood pressure in infants and children. Archives of Disease in Childhood, 48, 932.

Goldring, D., and Wohltmann, H. (1952). Flush method for blood pressure determinations in newborn infants. Fournal of Pedictrics, 40, 285.

Hamilton, W. F., Woodbury, R. A., and Harper, H. T., Jr. (1936). Physiologic relationships between intrathoracic, intraspinal and arterial pressures. Fournal of the American Medical Association, $107,853$.

Long, M., Dunlop, J. R., and Holland, W. W. (1971). Blood pressure recording in children. Archives of Disease in Childhood, 46, 636.

Moss, A. J., and Adams, F. H. (1964). Flush blood pressure and intra-arterial pressure. A comparison of methods in infants. American fournal of Diseases of Children, 107, 489.

Moss, A. J., and Adams, F. H. (1968). Heart Disease in Infants, Children and Adolescents, p. 65. Williams and Wilkins, Baltimore.

Moss, A. J., Liebling, W., and Adams, F. H. (1958). The flush method for determining blood pressures in infants. II. Normal values during the first year of life. Pediatrics, 21, 950.

Rudolph, A. M., Heymann, M. A., and Spitznas, U. (1972). Hemodynamic considerations in the development of narrowing of the aorta. American fournal of Cardiology, 30, 514.

Shinebourne, E. A. (1974). Growth and development of the cardiovascular system: functional development. In Scientific Foundations of Paediatrics, p. 198. Ed. by J. A. Davis and J. Dobbing Heineman, London.

Correspondence to Dr. M. de Swiet, The Cardicthoracic Institute, Brompton Hospital, Fulham Road, London SW3 6HP. 